\title{
Defining the optimal dose of radiation in leukemic patients with extramedullary lesions
}

\author{
Jin Ho Song, Seok Hyun Son, Ju Hwan Lee, Su Mi Chung, Hong Seok Jang and Byung Ock Choi*
}

\begin{abstract}
Background: Analysis of the clinical response of extramedullary lesions in leukemic patients treated with radiation therapy (RT) and defining the optimal dose of radiation.

Methods: Forty-two extramedullary lesions found in 24 leukemic patients treated with RT were reviewed. The radiation was delivered usually 2 Gy/day, up to a median of 20 Gy (range: 18.0-40.8). The clinical response and symptom palliation effect were analyzed. The factors affecting the response were also included in the analysis.

Results: After a median time of 7.9 weeks, the overall response rate was $76.2 \%$. A complete response (CR) was achieved in $35.7 \%$, a partial response in $40.5 \%$. The symptom was relieved in $85.7 \%$ sites. The overall response rate was better in patients whose initial tumor size was smaller than $10 \mathrm{~cm}^{2}(p=0.010)$ or who were treated with more than $25 \mathrm{~Gy}(p=0.031)$. The overall $\mathrm{CR}$ rate was also higher in those who had smaller tumors (smaller than $6 \mathrm{~cm}$ or $\left.30 \mathrm{~cm}^{2}\right)(p=0.015)$, or when the tumor was located in soft tissue $(p=0.029)$.

Conclusions: Extramedullary lesions in leukemic patients can be successfully treated with RT. The tumor response rate was excellent and symptom relief was achieved in almost all patients. There was a better response to treatment when the tumor was small or it was located in soft tissue. Although, there was no definite correlation between volume reduction and total dose, it seems that higher total dose more of than $25 \mathrm{~Gy}$ is needed for better response.
\end{abstract}

\section{Background}

Cure of leukemia is possible for significant numbers of patients after intensive treatment. However, clinical extramedullary lesions (EML) in leukemic patient negatively affect the prognosis [1]. EML in leukemic patients can occur at any age and in any organ or tissue throughout the body, especially soft tissue, skin, bones and lymph nodes [1-4]. However, it can also occur at other sites such as the gastrointestinal tract, genitourinary tract, heart, orbit and the sanctuary area, such as the testis and central nervous system [5-12].

The relatively rare incidence of EML has resulted in limited treatment experience, and there are no publications on randomized trials. Therefore, therapeutic decisions are usually based on retrospective studies and case reports. Chemotherapy is the most important treatment method $[1,13,14]$. However, on an individual basis, other modalities including surgical decompression or radiation

\footnotetext{
* Correspondence: choibo67@catholic.ac.kr

Department of Radiation Oncology, College of Medicine, The Catholic University of Korea, Seoul, Korea
}

therapy (RT) are sometimes clinically necessary [2,3,14-16].

$\mathrm{RT}$ is effective and can be used for localized lesions that cause symptoms [13-17]. However, there is no literature specifying guidelines for radiation oncologists in the treatment of patients with EML. As a result, the dose or fractionation schedule and radiation treatment method varies among institutions and patients. Therefore, we reviewed the clinical response of EML treated by RT.

\section{Methods}

\section{Patients and tumor characteristics}

We retrospectively reviewed the database at the St. Mary's Hospital, College of Medicine, the Catholic University of Korea from between January 2003 and December 2008. There were 37 patients and 88 sites treated with RT. The median follow-up time was 12.8 months (range: 1.9-80.2). To obtain objective clinical response results, we analyzed 24 patients and 42 sites whose follow up imaging study exists. There were 11 males and
C Biomed Central

(ㄷ) 2011 Song et al; licensee BioMed Central Ltd. This is an Open Access article distributed under the terms of the Creative Commons Attribution License (http://creativecommons.org/licenses/by/2.0), which permits unrestricted use, distribution, and reproduction in any medium, provided the original work is properly cited. 
13 female patients with a median age of 30 years old (range: 5-69). Most of the patients had acute myeloid leukemia (AML) as a primary disease (75.0\%) and the others were acute lymphcytic leukemia (ALL) (20.8\%) or CML (chronic myeloid leukemia) (4.2\%) patients.

In seven (29.2\%) patients, they developed before achieving the first complete remission. Of these patients, two patients had EML initially at the time of the leukemia diagnosis. In eleven $(45.8 \%)$ patients, EML developed as a first sign of the first leukemia relapse. Of the rest of patients, EML developed during or after the treatment for leukemia relapse. There were 14 patients with a history of bone marrow transplantation and 9 patients receiving a total body irradiation for the conditioning.

The diagnostic workup study included history taking, physical examination and imaging studies. Computed tomography $(\mathrm{CT})$ was acquired in 13 sites and magnetic resonance imaging (MRI) was performed for 29 sites. Of the 42 sites, 14 (33.3\%) sites were pathologically confirmed to granulocytic sarcoma. In the other sites, EML was diagnosed based on clinical evidences. Nineteen (45.2\%) tumors were located in bone, which was the most commonly affected site. Of the remaining 16 (38.1\%) tumors were located in soft tissue, $5(11.9 \%)$ in lymph nodes and $2(4.8 \%)$ in solid organs (one in brain, one in testis). The initial median tumor size was $4.8 \mathrm{~cm}$ (range: $1.1-15.0$ ) or $10.1 \mathrm{~cm}^{2}$ (range: $0.9-54.0$ ). The initial median tumor volume was $43.3 \mathrm{~cm}^{3}$ (range: 1.5 247.5). The patients and tumor characteristics are summarized in Table 1.

\section{Treatment characteristics}

Radiation was delivered usually once daily at 2 Gy, up to a median of 20 Gy (range: 18-40.8) with 6 or $10 \mathrm{MV}$ photon beams. The daily dose was lower than 2 Gy (1.7 or 1.8 Gy) for 10 sites, 2 Gy for 31 sites and 2.5 Gy in only one site. The overall median treatment time was 2.1 weeks (range: 0.9-6.0). Concurrent chemotherapy was delivered during the RT in 9 sites. Four patients received AML-like intensive chemotherapy, 3 patients received intra-thecal chemotherapy and 2 patients received imatinib.

\section{Response evaluation}

The size of tumors was measured on initial diagnostic CT or MRI images. The largest tumor dimension (LD), as well as the dimension perpendicular to it, was measured on transaxial CT or MRI images. The bidimensional tumor product (BP) was calculated as a product of the largest dimension and the dimension perpendicular to it. However, there were some limitations, such as some tumors were large in the cranio-caudal axis. To compensate for this problem, the tumor was contoured
Table 1 Patients and tumor characteristics

\begin{tabular}{|c|c|}
\hline Patients Characteristics & No (\%) \\
\hline \multicolumn{2}{|l|}{ Gender } \\
\hline Male & $11(45.8)$ \\
\hline Female & $13(54.2)$ \\
\hline Age, median (range) & $30(5-69)$ \\
\hline \multicolumn{2}{|l|}{ Primary disease } \\
\hline AML & $18(75.0)$ \\
\hline ALL & $5(20.8)$ \\
\hline$C M L$ & $1(4.2)$ \\
\hline \multicolumn{2}{|l|}{ Disease pattern } \\
\hline Before $1^{\text {st }}$ remission & $7(29.2)$ \\
\hline First manifestation of $1^{\text {st }}$ relapse & $11(45.8)$ \\
\hline After relapse & $6(25.0)$ \\
\hline History of SCT (+) & $14(58.3)$ \\
\hline History of TBI (+) & $9(37.5)$ \\
\hline Biopsy confirmed $(+)$ & $14(33.3)$ \\
\hline \multicolumn{2}{|l|}{ Tumor site } \\
\hline Bone & $19(45.2)$ \\
\hline Soft tissue & $16(38.1)$ \\
\hline Lymph nodes & $5(11.9)$ \\
\hline Solid organ & $2(4.8)$ \\
\hline Initial tumor size (LD), cm median (range) & $4.8(1.1-15.0)$ \\
\hline Initial tumor size (BP), $\mathrm{cm}^{2}$ median (range) & $10.13(0.88-54.0)$ \\
\hline Initial tumor volume, $\mathrm{cm}^{3}$ median (range) & $43.3(1.5-247.5)$ \\
\hline Total & 24 patients, 42 sites \\
\hline
\end{tabular}

Abbreviations: $\mathrm{AML}=$ Acute myeloid leukemia, $\mathrm{ALL}=$ Acute lymphocytic leukemia, $\mathrm{CML}=$ Chronic myeloid leukemia, $\mathrm{SCT}=\mathrm{Stem}$ cell transplantation, $\mathrm{TBI}=$ Total body irradiation, $\mathrm{LD}=$ Largest dimension, $\mathrm{BP}=$ Bidimensional product

with a modern radiation treatment planning system (CorePLAN, Seoul C\&J Inc., Korea) to calculate the tumor volume.

Post-therapy CT or MRI images were checked in the same way. Although the follow up period was not consistent in all tumors, the tumor response evaluation was performed according to RECIST criteria. The volume reduction rate was also calculated. The clinical or therapeutic factors that could have influenced the response were analyzed.

\section{Statistical analysis}

The treatment response was analyzed using the following factors: primary disease, tumor site, the use of chemotherapy, initial tumor size, follow up time and the total dose. Chi-square or Fischer's exact test were performed to determine if these factors influenced the response. Student's t-test was used for average comparison, and the Kaplan and Meier method was used for survival analysis. Linear logistic regression methods were used to analyze the relationship between the 
tumor dose and volume reduction rate. All results were considered statistically significant at the level of $p<0.05$ in a two-tailed test. SPSS ver. 12.0 for windows (SPSS Inc, Chicago, Illinois) was used for statistical analysis.

\section{Results}

\section{Tumor Response}

The first response evaluation was performed at a median of 1.9 weeks (range: 0-29.7) after the RT. There were 11 sites which the response evaluation was done directly after the RT. There were $12(28.6 \%)$ sites with a complete response (CR) and $17(40.5 \%)$ sites with a partial response (PR). The response rate $(\mathrm{CR}+\mathrm{PR})$ was $69.1 \%$. The second response evaluation was able to be acquired in only 20 sites. The median time was 11.7 weeks (range: 2.9-28.4) after RT. In comparison to first response evaluation, there were 6 sites that had a better response (PR to $\mathrm{CR}$ in 3 sites, SD to PR in 3 sites), and 12 sites showed the same results. However, two sites progressed. The one was a tumor on the anterior rib, which showed a PR the day after the RT (20.4 Gy in 12 fracions), but progressed in the second evaluation which was done 18.9 weeks after the RT. The other was a tumor on the distal femur which showed SD in the first evaluation (6.6 weeks after RT, 19.8 Gy in 11 fractions), but progressed in second evaluation (15.9 weeks after RT).

The overall response evaluation results are shown in Table 2. The median time for overall response evaluation was 7.9 weeks (range: 0-29.7). The overall CR was at $15(35.7 \%)$ sites, PR was at $17(40.5 \%)$ sites and SD at $8(19.0 \%)$ sites.

\section{Symptom palliation}

The symptom score was retrospectively evaluated in four scales determined by reading the chart notes. The pain or symptom was scored 0 to 3 from no pain or symptom, to mild, moderate or severe pain or symptom. The pain was relieved at $36(85.7 \%)$ sites and disappeared at $16(38.1 \%)$ sites. A decrease in the pain score of more than 2 points was observed in 17 patients and a decrease in 1 point in 19 patients. There were no significant differences in symptom palliation among the tumor sites (Table 3).
Table 3 The change of pain score after RT according to tumor sites (number of sites (\%))

\begin{tabular}{ccccc}
\hline $\begin{array}{c}\text { Decrease of pain } \\
\text { score }\end{array}$ & Bone & $\begin{array}{c}\text { Soft } \\
\text { tissue }\end{array}$ & $\begin{array}{c}\text { Lymph } \\
\text { nodes }\end{array}$ & $\begin{array}{c}\text { Solid } \\
\text { organ }\end{array}$ \\
\hline 2 points & $6(31.6)$ & $8(50.0)$ & $2(40.0)$ & $1(50.0)$ \\
1 point & $\begin{array}{c}10 \\
\text { No Change }\end{array}$ & $7(43.8)$ & $1(20.0)$ & $1(50.0)$ \\
No & $3(15.8)$ & $1(6.2)$ & $2(40.0)$ & $0(0.0)$ \\
\hline Disappeared & $4(21.1)$ & $9(56.3)$ & $2(40.0)$ & $1(50.0)$ \\
\hline Total & 19 & 16 & 5 & 2 \\
\hline
\end{tabular}

\section{Factors affecting tumor response}

There was no specific correlation between the initial tumor size and total radiation dose. The Pearson $\mathrm{R}^{2}$ was 0.046 for LD and total dose and 0.039 for BP and total dose, which suggests that the total dose was not increased according to initial tumor size. However, the tumor response was differed according to the initial tumor size and the total dose. The overall response rate was better in patients whose initial tumor size (BP) was smaller than $10 \mathrm{~cm}^{2}$ or in those patients treated with more than 25 Gy or BED 1030 Gy. Tumors received more than 25 Gy showed a $94.1 \%(16 / 17)$ response rate. In contrast, the overall response rate was only $64.0 \%$ $(16 / 25)$ with less than 25 Gy.

The overall CR rate was not affected by the total dose, but it was lower for those who had larger tumors. When the tumor was larger than $6 \mathrm{~cm}$ in LD or larger than $30 \mathrm{~cm}^{2}$ in $\mathrm{BP}$, the CR rate was lower. Of the 13 tumors larger than $6 \mathrm{~cm}$ only one tumor showed a CR. However, a CR was achieved in half $(14 / 29)$ of the small tumors less than $6 \mathrm{~cm}$. The tumor location was also important in the overall CR rate. When the tumor was located in soft tissue, a CR was better achieved than at other sites. The factors affecting the tumor response are listed in Table 4 and Table 5. The use of concurrent chemotherapy did not increase the response rate.

\section{Volume reduction rate}

The initial median volume of the tumor was $43.3 \mathrm{~cm}^{3}$. The median volume decreased to $11.4 \mathrm{~cm}^{3}$ and $3.3 \mathrm{~cm}^{3}$ in the first and second response evaluations. The

Table 2 Tumor response rate (number of sites (\%))

\begin{tabular}{cccc}
\hline & $\mathbf{1}^{\text {st }}$ response (42 sites) & $\mathbf{2}^{\text {nd }}$ response (20 sites) & Overall response (42 sites) \\
\hline CR & $12(28.6)$ & (from PR group) +3 & $15(35.7)$ \\
PR & $17(40.5)$ & (from SD group) +3 & $17(40.5)$ \\
SD & $13(30.9)$ & & $8(19.0)$ \\
PD & $0(0.0)$ & $($ from SD group) +2 & $2(4.8)$ \\
\hline Time after RT (weeks) & $1.9(0.0-47.7)$ & $11.7(2.9-28.4)$ & $7.9(0.0-47.7)$ \\
\hline
\end{tabular}

Abbreviations: $\mathrm{CR}=$ Complete response; $\mathrm{PR}=$ Partial response; $\mathrm{SD}=$ Stable disease; $\mathrm{PD}=$ Progressive disease

*median (range) 
Table 4 Factors affecting in overall response rate

\begin{tabular}{|c|c|c|c|c|c|}
\hline \multicolumn{2}{|c|}{ Factors ( $2 \times 2$ analysis) } & \multirow{2}{*}{$\frac{\text { Response }(\mathrm{CR}+\mathrm{PR})}{23}$} & \multirow{2}{*}{$\frac{\text { Non-response (SD + PD) }}{4}$} & \multirow{2}{*}{$\begin{array}{c}\text { Total } \\
27\end{array}$} & \multirow{2}{*}{$\frac{p \text {-value }}{0.128}$} \\
\hline Primary disease & Yes & & & & \\
\hline AML & No & 9 & 6 & 15 & \\
\hline RT site & Yes & 14 & 2 & 16 & 0.270 \\
\hline Soft tissue & No & 18 & 8 & 26 & \\
\hline Concurrent & Yes & 8 & 1 & 9 & 1.000 \\
\hline Chemotherapy & No & 24 & 9 & 33 & \\
\hline Initial size & Yes & 13 & 9 & 22 & $0.010^{*}$ \\
\hline $\mathrm{BP} \geq 10 \mathrm{~cm}^{2}$ & No & 19 & 1 & 20 & \\
\hline Initial size & Yes & 14 & 7 & 21 & 0.277 \\
\hline $\mathrm{LD} \geq 6.0 \mathrm{~cm}$ & No & 18 & 3 & 21 & \\
\hline Follow up time & Yes & 23 & 7 & 30 & 1.000 \\
\hline$\geq 2$ weeks & No & 9 & 3 & 12 & \\
\hline Total dose & Yes & 16 & 1 & 17 & $0.031^{*}$ \\
\hline$\geq 25 \mathrm{~Gy}$ & No & 16 & 9 & 25 & \\
\hline $\mathrm{BED}_{10}$ & Yes & 17 & 1 & 18 & $0.026^{*}$ \\
\hline$\geq 30 \mathrm{~Gy}$ & No & 15 & 9 & 24 & \\
\hline
\end{tabular}

Abbreviations: $\mathrm{AML}=$ Acute myeloid leukemia, $\mathrm{BP}=$ Bidimensional product, $\mathrm{LD}=$ Largest dimension, $\mathrm{BED}=$ Biologic effective dose

*Statistically significant factors

median volume reduction rate was $71.9 \%$ and $76.8 \%$, respectively. The overall median volume reduction rate was $74.7 \%$. The volume increased $13.0 \%$ and $83.1 \%$ in two sites, which were counted as a PD in response evaluation. There were no statistically significant factors affecting the volume reduction rate (Table 6). Although there was no definite linear correlation between the

Table 5 Factors affecting in overall CR rate

\begin{tabular}{cccccc}
\hline $\begin{array}{c}\text { Factors ( } \mathbf{2} \times \mathbf{2} \\
\text { analysis) }\end{array}$ & $\begin{array}{c}\text { CR (15 } \\
\text { sites) }\end{array}$ & $\begin{array}{c}\text { Non-CR (27 } \\
\text { sites) }\end{array}$ & Total & $\begin{array}{c}\boldsymbol{p} \text { - } \\
\text { value }\end{array}$ \\
\hline $\begin{array}{c}\text { Primary } \\
\text { disease }\end{array}$ & Yes & 10 & 17 & 27 & 0.810 \\
AML & No & 5 & 10 & 15 & \\
\hline RT site & Yes & 9 & 7 & 16 & $0.029^{*}$ \\
Soft tissue & No & 6 & 20 & 26 & \\
\hline Concurrent & Yes & 3 & 7 & 10 & 1.000 \\
Chemotherapy & No & 12 & 20 & 32 & \\
\hline Initial size & Yes & 0 & 7 & 7 & $0.038^{*}$ \\
BP $\geq 30$ cm & No & 15 & 20 & 35 & \\
\hline Initial size & Yes & 1 & 12 & 13 & $0.015^{*}$ \\
LD $\geq 6.0$ cm & No & 14 & 15 & 29 & \\
\hline Follow up time & Yes & 13 & 17 & 30 & 0.158 \\
$\geq 2$ weeks & No & 2 & 10 & 12 & \\
\hline Total dose & Yes & 8 & 9 & 17 & 0.326 \\
$\geq 25$ Gy & No & 7 & 18 & 25 & \\
\hline BED 10 & Yes & 8 & 10 & 18 & 0.347 \\
$\geq 30$ Gy & No & 7 & 17 & 24 & \\
\hline
\end{tabular}

Abbreviations: $\mathrm{CR}=$ Complete response $\mathrm{ML}=$ Acute myeloid leukemia, $\mathrm{BP}=$ Bidimensional product, $\mathrm{LD}=$ Largest dimension, $\mathrm{BED}=$ Biologic effective dose *Statistically significant factors total dose and volume reduction rate, the average volume reduction rate was higher in those who received more than 25 Gy (Figure 1).

\section{Overall survival}

The overall survival in patients with EML was poor; only five of 24 patients are still alive. The actuarial median survival time was 11.5 months (range: 2.3-59.0) after the diagnosis of EML. The 1 and 2-year overall survival rate was $50.0 \%$ and $41.3 \%$, respectively (Figure 2 ).

Table 6 Factors affecting in volume reduction rate

\begin{tabular}{cccc}
\hline Factors & & Mean Volume Reduction Rate (\%) & $\boldsymbol{p}$-value \\
\hline Primary disease & Yes & 75.0 & 0.077 \\
AML & No & 56.9 & \\
\hline RT site & Yes & 75.7 & 0.254 \\
Soft tissue & No & 64.1 & \\
\hline Concurrent & Yes & 78.7 & 0.248 \\
Chemotherapy & No & 65.3 & \\
\hline Initial size & Yes & 48.4 & 0.065 \\
BP $\geq 30 \mathrm{~cm}^{2}$ & No & 72.5 & 0.175 \\
\hline Initial size & Yes & 58.5 & \\
LD $\geq 6.0 \mathrm{~cm}$ & No & 73.0 & 0.877 \\
\hline Follow up time & Yes & 69.0 & \\
$\geq 2$ weeks & No & 67.3 & 0.178 \\
\hline Total dose & Yes & 76.6 & 0.140 \\
$\geq 25$ Gy & No & 63.0 & \\
\hline BED 10 & Yes & 76.9 & 62.2 \\
$\geq 30$ Gy & No &
\end{tabular}

Abbreviations: $\mathrm{AML}=$ Acute myeloid leukemia, $\mathrm{BP}=$ Bidimensional product, $\mathrm{LD}$ $=$ Largest dimension, $\mathrm{BED}=$ Biologic effective dose 


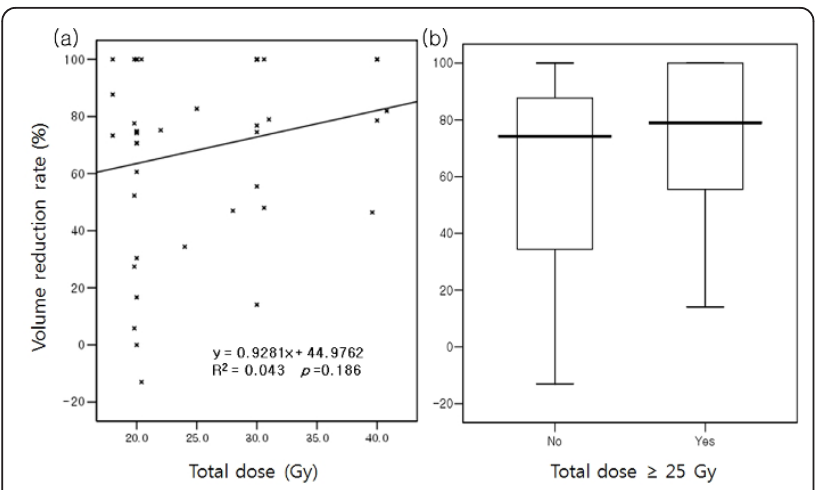

Figure 1 The volume reduction rate according to the total radiation dose. (a) Linear logistic regression analysis between the total dose and volume reduction rate. (b) The box-plot of the average volume reduction rate according to total dose.

\section{Discussion}

The rare incidence of EML and the variable location of the lesions resulted in a limited clinical experience. Although, EML can occur in any organ or tissue throughout the body, in our study, the most common site was the bone. Soft tissue and lymph nodes were also the major sites of involvement.

The median survival of patients with EML in our study was 11.5 months. It is well known that the presence of EML in leukemic patients is generally associated with a poor clinical outcome with a shorter survival time $[1,3,14]$. The development of EML may imply that some important signaling pathways exist,

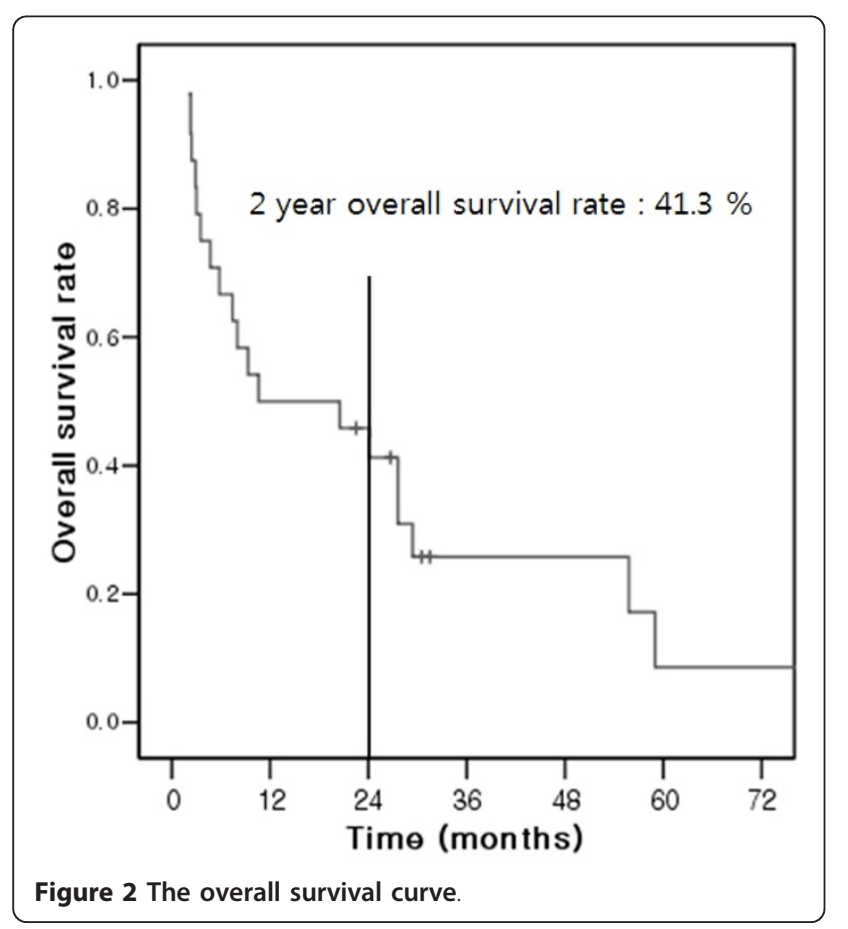

which are associated with migration of leukemic cells to the extramedullary organs and tissues.

Therefore, even though the treatment of EML is not well established, many authors suggest that intensive chemotherapeutic agents are the cornerstone in the treatment $[4,13,14]$. Lan reported that patients undergoing chemotherapy for EML had a significantly longer survival than those not receiving chemotherapy [14]. Yamauchi also suggested that the use of intensive chemotherapy can reduce the risk of subsequent development of leukemia in non-leukemic granulocytic sarcoma patients [4]. On the other hand, the role of RT in the treatment of EML is not well established. Tsimberidou reported RT does not improve the overall or failure-free survival [13]. However, in clinical situations, other treatment modalities except chemotherapy, including surgical decompression or RT, are also necessary on an individual basis for the management of pain and/or other symptoms. Also in some cases, there are patients who cannot undergo chemotherapy because of their poor medical condition [14].

RT is preferred to surgery in many cases because it is non-invasive and leukemic cells are known as extremely radiosensitive. However, the optimal irradiation dose has not been established because of the limited clinical experience. There are some reports treated the EML successfully with RT with or without chemotherapy $[4,7,13,14,16-22]$. However, the many reports dose not describe the radiation technique or dose. Although, response rates of leukemic infiltrates have been reported with doses as low as 4 Gy, the need for higher doses up to $40 \mathrm{~Gy}$ in certain locations is also recognized [23,24]. In a recent report by Bakst et al. [17], they recommend 24 Gy in 12 fractions. In our study, almost all patients received more than 20 Gy except for one patient whose treatment was interrupted due to a poor medical condition. The overall response rate was $76.2 \%$ and the symptom response rate was $85.7 \%$, which suggests that in almost all cases the palliation aim can be achieved with RT. Although, there was no correlation with symptom control and RT dose, the overall response rate was better in those treated with more than 25 Gy (or BED 1030 Gy) or in those with an initial tumor size smaller than $10 \mathrm{~cm}^{2}$.

A CR was achieved in one third (35.8\%) of the sites treated, and there is a higher chance of a CR when the tumor is located in the soft tissue. However, when the tumor is large (more than $6 \mathrm{~cm}$ or $30 \mathrm{~cm}^{2}$ ), it seems that a higher RT dose is needed. Some authors have also suggested a relationship between the size of the tumors and the total irradiation dose [24].

The limitation of this study was its retrospective study design without controls, small case numbers and insufficient medical record of symptom change. However, this 
is an early study that focuses on the role of radiation for the treatment of EML in leukemic patients.

\section{Conclusions}

In conclusion, from this retrospective study, we conclude that EML can be managed successfully with RT. The tumor response rate was excellent and symptom relief was achieved in almost all patients, at least in the short term. Although, there was no definite correlation between volume reduction and total dose, it seems that a higher total dose of more than 25 Gy or $\mathrm{BED}_{10} 30 \mathrm{~Gy}$ is needed for a better response. We also suggest that a higher total radiation dose may be needed when the EML is large or located in non-soft tissue sites. In addition, we suggest that at least 20 Gy may be enough for symptom palliation in leukemic patients with EML. Further studies are needed for detailed RT dose schedule depending upon the tumor size.

\section{Acknowledgements}

The authors wish to acknowledge the financial support of the Catholic Medical Center Research Foundation made in the program year of 2010.

\section{Authors' contributions}

JHS carried out the study and drafted the manuscript. BOC designed the study and gave final approval for publication. SHS and SMC participated in the design of the study and helped to perform the statistical analyses. JHL and HSJ participated in the analysis and the data interpretation. SHS, JHL participated in the data acquisition and analysis. All authors have read and approved the final manuscript.

\section{Competing interests}

The authors declare that they have no competing interests.

Received: 31 March 2011 Accepted: 6 October 2011

Published: 6 October 2011

\section{References}

1. Cunningham I: Extramedullary sites of leukemia relapse after transplant. Leuk Lymphoma 2006, 47:1754-1767.

2. Breccia M, Mandelli F, Petti MC, D'Andrea M, Pescarmona E, Pileri SA, Carmosino I, Russo E, De Fabritiis P, Alimena G: Clinico-pathological characteristics of myeloid sarcoma at diagnosis and during follow-up: report of 12 cases from a single institution. Leuka Res 2004, 28:1165-1169.

3. Paydas S, Zorludemir S, Ergin M: Granulocytic sarcoma: 32 cases and review of the literature. Leukemia 2006, 47:2527-2541.

4. Yamauchi K, Yasuda M: Comparison in treatments of nonleukemic granulocytic sarcoma: report of two cases and a review of 72 cases in the literature. Cancer 2002, 94:1739-1746.

5. Lin C, Wu K, Lin W, Tsai J, Peng C, Chen A: Granulocytic sarcoma of the colon in a child with acute myeloid leukemia presenting as hematochezia. J Pediatr Hematol Oncol 2008, 30:981-983.

6. Spethmann S, Heuer R, Hopfer H, Tuinmann G: Myeloid sarcoma of the prostate as first clinical manifestation of acute myeloid leukaemia. Lancet Oncol 2004, 5:62-63.

7. Mignano JE, Chan MD, Rosenwald IB, Kimmelstiel CD, Wolfe LC: Intracardiac chloroma. J Pediatr Hematol Oncol 2009, 31:977-979.

8. Lo W, Kuo C, Kuo M, Fang P: Isolated conjunctival myeloid sarcoma as a presenting sign of acute leukemia. Chang Gung Med J 2010, 33:334-337.

9. Colovic N, Colovic M, Cemerikic V, Terzic T, Ivanovic S, Skender M, Boskovic D: Granulocytic sarcoma of the brain in a patient with acute myeloid leukemia. Acta Chir lugosl 2004, 51:129-131.
10. Eser B, Cetin M, Kontas O, Unal A, Er O, Coskun HS, Altinbas M: Facial Nerve Paralysis and Paraplegia as Presenting Symptoms of Acute Myeloid Leukemia. Jpn J Clin Oncol 2001, 31:86-88.

11. Toki H, Okabe K, Kimura Y, Kiura K, Shibata H, Hara K, Moriwaki S, Nanbu T, Iwashita A: Granulocytic Sarcoma of the Intestine as a Primary Manifestation Nine Months Prior to Overt Acute Myelogenous Leukemia. Jpn J Clin Oncol 1987, 17:79-85.

12. Yamamoto K, Hamaguchi H, Nagata K, Hara M, Tone O, Tomita H, Ito U: Isolated Recurrence of Granulocytic Sarcoma of the Brain: Successful Treatment with Surgical Resection, Intrathecal Injection, Irradiation and Prophylactic Systemic Chemotherapy. Jpn J Clin Oncol 1999, 29:214-218.

13. Tsimberidou AM, Kantarjian HM, Estey E, Cortes JE, Verstovsek S, Faderl S, Thomas DA, Garcia-Manero G, Ferrajoli A, Manning JT, et al: Outcome in patients with nonleukemic granulocytic sarcoma treated with chemotherapy with or without radiotherapy. Leukemia 2003, 17:1100-1103.

14. Lan T, Lin D, Tien H, Yang R, Chen C, Wu K: Prognostic factors of treatment outcomes in patients with granulocytic sarcoma. Acta Haematol 2009, 122:238-246.

15. Landis DM, Aboulafia DM: Granulocytic sarcoma: an unusual complication of aleukemic myeloid leukemia causing spinal cord compression. A case report and literature review. Leukemia 2003, 44:1753-1760.

16. Olcay L, Aribas BK, Gke M: A patient with acute myeloblastic leukemia who presented with conus medullaris syndrome and review of the literature. J Pediatr Hematol Oncol 2009, 31:440-447.

17. Bakst RL, Tallman MS, Douer D, Yahalom J: How I treat extramedullary acute myeloid leukemia. Blood 2011

18. Skeete DH, Cesar-Rittenberg P, Jong R, Murray SK, Colgan TJ: Myeloid sarcoma of the vagina: a report of 2 cases. J Low Genit Tract Dis 2010, 14:136-141.

19. Antic D, Verstovsek S, Elezovic I, Grujicic D, Gotic M, Bila J, Perunicic M, Jakovic L: Spinal epidural granulocytic sarcoma in non-leukemic patient. Int J Hematol 2009, 89:95-97.

20. Bhatia N, Wallace T, Divgi A, Short V: Myeloid sarcoma presenting as an isolated nodule in a patient with acute myelogenous leukemia. J Drugs Dermatol 2007, 6:447-450.

21. Rodriguez Perez A, Lopez Carrizosa MC, Villalon Blanco L, Samper Ots PM, Ortiz Cruz E: Granulocytic sarcoma of the right humerus in a nonleukaemia patient. Clin Transl Oncol 2008, 10:758-760.

22. Verra WC, Snijders TJ, Seute T, Han KS, Nieuwenhuis HK, Rutten GJ: Myeloid sarcoma presenting as a recurrent, multifocal nerve root entrapment syndrome. J Neurooncol 2009, 91:59-62.

23. Neiman RS, Barcos M, Berard C, Bonner H, Mann R, Rydell RE, Bennett JM: Granulocytic sarcoma: a clinicopathologic study of 61 biopsied cases. Cancer 1981, 48:1426-1437.

24. Edward C, Halperin CAP LW: Perez and Brady's Principles and Practice of Radiation Oncology , 52004.

\section{Pre-publication history}

The pre-publication history for this paper can be accessed here: http://www.biomedcentral.com/1471-2407/11/428/prepub

doi:10.1186/1471-2407-11-428

Cite this article as: Song et al:: Defining the optimal dose of radiation in leukemic patients with extramedullary lesions. BMC Cancer 2011 11:428.

\section{Submit your next manuscript to BioMed Central and take full advantage of:}

- Convenient online submission

- Thorough peer review

- No space constraints or color figure charges

- Immediate publication on acceptance

- Inclusion in PubMed, CAS, Scopus and Google Scholar

- Research which is freely available for redistribution 